\title{
Characterization of a Virus from Pigeonpea with Affinities to Species in the Genus Aureusvirus, Family Tombusviridae
}

P. Lava Kumar, International Crops Research Institute for the Semi-Arid Tropics (ICRISAT), Patancheru-502324, India; A. T. Jones, Scottish Crop Research Institute, Invergowrie DD2 5DA, Scotland, UK; P. Sreenivasulu, Sri Venkateswara University, Tirupati-517502, India; B. Fenton, Scottish Crop Research Institute, Invergowrie, and D. V. R. Reddy, ICRISAT, Patancheru

\begin{abstract}
Kumar, P. L., Jones, A. T., Sreenivasulu, P., Fenton, B., and Reddy, D. V. R. 2001. Characterization of a virus from pigeonpea with affinities to species in the genus Aureusvirus, family Tombusviridae. Plant Dis. 85:208-215.

In attempts to identify the causal agent of pigeonpea sterility mosaic disease (PSMD), which is transmitted by eriophyid mites, a virus was isolated with great difficulty from some PSMDaffected pigeonpea (Cajanus cajan) plants from different locations in India. Once isolated from pigeonpea, the virus was transmitted readily by mechanical inoculation to several herbaceous species, reaching very high concentrations in some species. The virus was transmitted experimentally through soil to herbaceous test plants but not to pigeonpea. When virus particles were purified and inoculated mechanically to healthy pigeonpea, the virus induced necrosis in inoculated leaves only and did not spread systemically. Therefore, the virus is not the causal agent of PSMD. The virus has isometric particles approximately $30 \mathrm{~nm}$ in diameter that sediment as a single component and had a buoyant density in $\mathrm{CsCl}$ and $\mathrm{Cs}_{2} \mathrm{SO}_{4}$ of 1.34 and $1.27 \mathrm{~g} \cdot \mathrm{cc}^{-1}$, respectively. Purified virus particle preparations contained a single major protein of approximately $44 \mathrm{kDa}$ and three RNA species of approximately 4,300, 2,700, and 1,500 nucleotides. Only the largest RNA species was infective to plants; the two smaller species were encapsidated subgenomic species of the $3^{\prime}$ end of the larger genomic RNA. The viral genome was sequenced and showed 93\% homology to that of Pothos latent virus (PoLV), a recently described virus in the genus Aureusvirus, family Tombusviridae, and was indistinguishable from PoLV in gel double-diffusion serological tests. This virus, therefore, is regarded as a pigeonpea isolate of PoLV (PoLV-PP). In field studies in different locations in India, enzyme-linked immunosorbent assay and reverse-transcriptase polymerase chain reaction detected PoLV-PP in 10.7\% of PSMD-affected and $8.1 \%$ of asymptomatic pigeonpea plants. The significance of these findings is discussed.
\end{abstract}

Additional keywords: cDNA, nucleotide sequence

Pigeonpea (Cajanus cajan (L.) Millsp.) is a drought-resistant pulse crop cultivated widely in the tropics and subtropics of Asia, Africa, and the Caribbean for its protein-rich seeds. India accounts for nearly $80 \%$ of the world's pigeonpea production (20). Sterility mosaic disease of pigeonpea (PSMD), a virus-like disease of

Corresponding author: A. T. Jones

E-mail: t.jones@scri.sari.ac.uk

This document is an output from a project funded by the UK Department for International Development (DFID), under a holdback grant to ICRISAT and SCRI (Project No. R6407[H]). The views expressed are not necessarily those of DFID. Work at SCRI is grant aided by the Scottish Executive Rural Affairs Department (SERAD). Studies on nonindigenous organisms was done under the conditions of a license from SERAD.

Accepted for publication 3 November 2000.

Publication no. D-2000-1211-01R

This article is in the public domain and not copyrightable. It may be freely reprinted with customary crediting of the source. The American Phytopathological Society, 2001. unknown etiology, severely affects pigeonpea production in India and other Asian countries (3). In most genotypes, infection early in the season can cause yield losses of $>90 \%$, with an estimated annual loss in 1975-80 in India alone of over $\$ 70$ million (8). The causal agent of PSMD is transmitted in nature by the eriophyid mite, Aceria cajani (Channabasavanna), and experimentally by grafting, but not by mechanical inoculation of sap (3). All attempts to characterize the causal agent of this disease have been unsuccessful but, based on symptoms and mode of transmission, it is presumed to be a virus $(3,21)$.

In the last few years, considerable progress has been achieved in the characterization of some mite-transmitted agents infecting dicotyledonous plants. For example, the characterization of the mitetransmitted Blackcurrant reversion associated virus (BRAV) was achieved after transmitting it to herbaceous hosts (13), whereas Peach mosaic virus (PMV) was characterized after purification directly from the natural woody host (4). We used a protocol to transfer the potential viral agent of PSMD to herbaceous hosts on the assumption that it exists in low titer and is distributed erratically in pigeonpea and that host polyphenolic compounds interfere with virus extraction and/or infectivity. This procedure resulted in the isolation of a virus with isometric particles that is new to pigeonpea. This article reports on the purification and characterization of this virus, and shows that it is very closely related to the newly described member of the tombusvirus genus, Pothos latent virus (PoLV; 25) from pothos (Scindapus aureus), and that it is not the causal agent of PSMD. It is referred to as the pigeonpea isolate of PoLV (PoLV-PP).

\section{MATERIALS AND METHODS}

Virus isolation. PSMD-affected pigeonpea leaves from experimental plots and farms in India were used for virus isolation. About $20 \mathrm{~g}$ of leaf material was macerated in $100 \mathrm{ml}$ of $50 \mathrm{mM}$ phosphate buffer, pH 7 , containing $0.2 \%$ monothioglycerol and $1 \%$ ovalbumin. The extract was filtered through cheesecloth and clarified by centrifuging at $12,000 \times g$ for 5 min. The supernatant fluid was concentrated by centrifuging at $48,000 \mathrm{rpm}$ for 60 min at $4^{\circ} \mathrm{C}$ in a Beckman 50.2Ti rotor. The pellets were dissolved in $500 \mu \mathrm{l}$ of phosphate buffer and inoculated mechanically onto corundum-dusted leaves of herbaceous hosts (Table 1 ) that were maintained in an aphid-proof glasshouse at 18 to $26^{\circ} \mathrm{C}$. Following some of these inoculations, a few necrotic local lesions were noted on a few Chenopodium quinoa plants. For further studies, a virus isolate obtained through single lesion transfer from PSMDaffected material from the International Crops Research Institute for the Semi-Arid Tropics (ICRISAT), Patancheru, was used and is here called a pigeonpea isolate of PoLV (PoLV-PP).

Host range and biological assay. Sap from PoLV-PP-infected $C$. quinoa leaves was extracted in $10 \mathrm{mM}$ phosphate buffer, $\mathrm{pH} \mathrm{7,} \mathrm{and} \mathrm{the} \mathrm{inoculum} \mathrm{applied} \mathrm{to} \mathrm{the}$ leaves of various herbaceous test plants (Table 1). Infection of test plants was assessed by return inoculation to $C$. quinoa, using sap from inoculated and uninoculated apical leaves separately. The virus was maintained in culture by serial passage in Nicotiana clevelandii and was also pre- 
served by storing freeze-dried infected $N$. clevelandii leaves at $-20^{\circ} \mathrm{C}$.

Tests for soil transmission. In order to assess the ability of PoLV-PP to be acquired by roots through soil, test plants were allowed access to PoLV-PP in two different kinds of experiment. In the first, five plants each of $N$. clevelandii, $N$. benthamiana, and pigeonpea cv. ICP8863 were grown in individual pots containing sterilized compost and the soil was watered once with PoLV-PP-infected N. benthamiana leaf sap diluted in distilled water $(0.25$ $\mathrm{gm} \cdot \mathrm{ml}^{-1}$ ), taking care to avoid contaminating the aerial parts of the test plants. Control plant pots were watered with tap water only. In the second experiment, soil and root debris collected from around PoLV-PP-infected $N$. clevelandii in pots was mixed and placed carefully into sterile pots to a depth of about 1 to 2 in. $(5 \mathrm{~cm})$. This contaminated soil was then covered with about 2- to 3-in. (5- to 7-cm) layer of sterile compost into which young seedlings of $N$. clevelandii and pigeonpea cv. ICP8863 (raised in sterile compost) were transplanted to a depth no lower than the sterile soil layer. In this way, only actively growing roots of plants were able to reach the contaminated soil layer. Five plants of each test species were planted in individual pots. Both kinds of experiment were repeated twice using the same numbers of plants and all test plants were assayed for infection with PoLV-PP by enzyme-linked immunosorbent assay (ELISA) about 3 weeks after each experiment was begun.

Virus purification. PoLV-PP was purified from infected $N$. clevelandii leaves harvested 2 weeks post-inoculation (pi) using a slightly modified protocol used to purify BRAV (13). Leaves were ground in $50 \mathrm{mM}$ phosphate buffer, $\mathrm{pH} \mathrm{7,} \mathrm{containing}$ $0.2 \%$ monothioglycerol ( $2 \mathrm{ml}$ of buffer per gram of leaf). The extract was filtered through muslin cloth and the filtrate clarified by emulsifying with an equal volume of chloroform. The emulsion was broken by centrifuging at $12,000 \times g$ for $15 \mathrm{~min}$ and the aqueous phase concentrated by centrifuging at $48,000 \mathrm{rpm}$ for $60 \mathrm{~min}$ in a Beckman 50.2Ti rotor. The pellets were resuspended in 1 to $3 \mathrm{ml}$ of $50 \mathrm{mM}$ phosphate buffer and layered on sucrose density gradient columns prepared by freezethawing a $25 \%$ sucrose solution in $50 \mathrm{mM}$ phosphate buffer, $\mathrm{pH} \mathrm{7}$, then centrifuged at $36,000 \mathrm{rpm}$ for $2 \mathrm{~h}$ in a Beckman SW41 rotor. The gradient tubes were fractionated by upward displacement in an ISCO ultraviolet gradient fractionator and fractions corresponding to the main absorbance peak were pooled, diluted with 2.5 volumes of $50 \mathrm{mM}$ phosphate buffer, and concentrated by centrifuging at $45,000 \mathrm{rpm}$ for $90 \mathrm{~min}$ in a Beckman SW50 rotor. The virus-containing pellets were resuspended in a minimal volume of $50 \mathrm{mM}$ phosphate buffer.

Buoyant density. Cesium chloride or cesium sulfate in $10 \mathrm{mM}$ phosphate buffer, $\mathrm{pH} \mathrm{7,} \mathrm{was} \mathrm{added} \mathrm{to} \mathrm{purified} \mathrm{virus} \mathrm{particle}$ preparations to an initial density of 1.36 and $1.34 \mathrm{~g} \cdot \mathrm{cc}^{-1}$, respectively. The solution was filtered through glass wool and the gradients centrifuged in a Beckman SW50.1 rotor at $40,000 \mathrm{rpm}$ at $10^{\circ} \mathrm{C}$ for 16 h. Gradients were fractionated by upward displacement and the density of the fractions determined using a refractometer.

Electron microscopy. Sap from infected leaves or purified particle preparations on carbon-coated grids were washed with eight drops of $1.5 \%$ phosphotungstic acid (PTA), pH 6.5. After drying, grids were observed in a JEOL JEM 100SX transmission electron microscope at $\times 30,000$ mag-

Table 1. Experimental host range of Pothos latent virus-pigeonpea isolate

\begin{tabular}{|c|c|}
\hline Test plant species & Type of symptoms \\
\hline \multicolumn{2}{|l|}{ Local lesion hosts } \\
\hline Beta vulgaris ${ }^{\mathrm{a}}$ & $N L L^{b}$ \\
\hline Brassica napa & Large irregular shaped NLL on inoculated leaves which coalesced to form large necrotic areas \\
\hline Chenopodium amaranticolor ${ }^{\mathrm{a}}$ & Round NLL with purple margins \\
\hline C. murale & Pinpoint NLL \\
\hline C. quinoa ${ }^{\mathrm{a}}$ & Pinpoint to large NLL 4 days post-inoculation \\
\hline Nicotiana sylvestris & Local necrotic spots \\
\hline N. tabacum cv. Samsun ${ }^{a}$ & Irregular shaped NLL \\
\hline N. tabacum cv. Xanthi $\mathrm{n} / \mathrm{n}^{\mathrm{c}}$ & Irregular shaped white NLL \\
\hline N. tabacum cv. Xanthi N/Nc & Irregular shaped white NLL \\
\hline Petunia compacta & Few necrotic lesions \\
\hline Spinacia oleraceae ${ }^{\mathrm{c}}$ & Large round sunken necrotic lesions \\
\hline Tetragonia expansa ${ }^{\mathrm{c}}$ & NLL and systemic necrotic spots on a few leaves \\
\hline \multicolumn{2}{|l|}{ Systemic hosts } \\
\hline Gomphrena globosa ${ }^{\mathrm{c}}$ & $\begin{array}{l}\text { Large NLL with purple margins. Systemic infection confined to mid rib portion of a few leaves (veinal } \\
\text { purpling) }\end{array}$ \\
\hline N. benthamiana ${ }^{\text {a }}$ & Systemic wilting followed by death of the plant \\
\hline N. clevelandii $^{\mathrm{a}}$ & $\begin{array}{l}\text { Large irregular shaped NLL and pinpoint to large necrotic lesions on non-inoculated leaves. } \\
\text { Death of the plant after 3-4 weeks post inoculation due to necrosis }\end{array}$ \\
\hline N. hispens & Systemic necrotic infection resulting in death of apical shoot of the plant \\
\hline \multicolumn{2}{|l|}{ Symptomless hosts } \\
\hline Lycopersicon esculentum & Symptomless or virus detected in only inoculated leaves \\
\hline N. debnyii & Symptomless or virus detected in only inoculated leaves \\
\hline N. glutinosa & Symptomless or virus detected in only inoculated leaves \\
\hline N. occidentalis $37 \mathrm{~B}^{\mathrm{a}}$ & Symptomless or virus detected in only inoculated leaves \\
\hline Physalis floridana & Symptomless or virus detected in only inoculated leaves \\
\hline \multicolumn{2}{|l|}{ Immune } \\
\hline Brassica pekinensis & No symptoms and no virus detected \\
\hline Cucurbita pepo ${ }^{\text {a }}$ & No symptoms and no virus detected \\
\hline N. occidentalis $\mathrm{P} 1$ & No symptoms and no virus detected \\
\hline N. rustica & No symptoms and no virus detected \\
\hline N. tabacum cv. J & No symptoms and no virus detected \\
\hline N. tabacum cv. White Burley & No symptoms and no virus detected \\
\hline Phaseolus vulgaris ${ }^{\mathrm{a}}$ & No symptoms and no virus detected \\
\hline Vicia faba cv. Minden & No symptoms and no virus detected \\
\hline V. faba cv. The Sutton & No symptoms and no virus detected \\
\hline
\end{tabular}

${ }^{a}$ Used for initial inoculation of concentrated pigeonpea extracts.

b NLL = necrotic local lesions.

${ }^{c}$ Systemic spread of virus in one of three trials. 
nification. A catalase crystal grid was used to calibrate the microscope before photographing particles for size measurements.

Antibody production and serology. An antiserum to purified PoLV-PP particles was produced in a New Zealand White rabbit by three separate subcutaneous injections, each of $100 \mu \mathrm{g}$ of purified virus in Freund's incomplete adjuvant, made at 2week intervals. Antiserum was collected 4 weeks after the last injection and its titer determined in agarose gel double-diffusion (Ouchterlony) tests. Purified virus particle preparations were tested in agarose gel double-diffusion tests for reactivity with antisera to the following viruses with icosahedral particles; Carnation mottle virus, Cowpea mosaic virus, Cowpea mottle virus, Cymbidium ringspot virus, Elderberry latent virus (= Pelargonium ringspot virus; 7), Galinsoga mosaic virus, Hibiscus chlorotic ringspot virus, Pelargonium flower break virus, Pothos latent virus, Saguaro cactus virus, and Tomato bushy stunt virus.

Direct antigen coating (DAC)-ELISA was used to detect the virus in leaf material (19). Alkaline phosphatase (ALP)-labeled antirabbit antibodies were used to detect the immobilized antigen-antibody complex and $p$-nitrophenylphosphate (Sigma, Gillingham, UK) was used as substrate. After $1 \mathrm{~h}$ of incubation, readings were taken at $A_{405 \mathrm{~nm}}$ in a Multiscan Plus ELISA plate reader (Labsystems, Helsinki, Finland).

Analysis of virus protein and nucleic acid. The size of the viral coat protein was determined by electrophoresis of denatured purified virus particle preparations in a $12 \%$ sodium dodecyl sulfate-polyacrylamide gel electrophoresis (SDS-PAGE) stained with Coomassie brilliant blue (12). Prestained protein markers (NOVEX, Frankfurt, Germany) were used as size markers. Viral nucleic acid was isolated from purified virus particle preparations using the Plant RNeasy kit (QIAGEN, West Sussex, UK) following the manufacturer's protocol. The RNA samples were analyzed in a $1 \%$ formaldehyde denaturing agarose gel (26) and the gels stained with ethidium bromide and viewed on a UVtransilluminator.

Infectivity of viral RNA was assessed by mechanically inoculating RNA preparations onto $C$. quinoa leaves washed previously with bentonite buffer (10\% bentonite in $0.01 \mathrm{M}$ Tris-HCl, $\mathrm{pH}$ 7.6) and dusted with corundum. The infectivity of each RNA species was determined by inoculating the eluted viral RNA species separated on a $1 \%$ agarose gel (26). To determine whether the viral RNA contained a poly A tract at the 3' end, the Oligotex mRNA kit (QIAGEN) was used following the manufacturer's recommended protocol.

For Northern blot analysis, denatured RNA was transferred from formaldehydeagarose gels to Hybond-N (Amersham, Buckinghamshire, UK) and fixed by UVcrosslinking (UV-Stratalinker, Stratagene, Cambridge, UK). The blots were probed with digoxygenin (DIG)-dUTP-labeled (Roche, East Sussex, UK) virus comple-

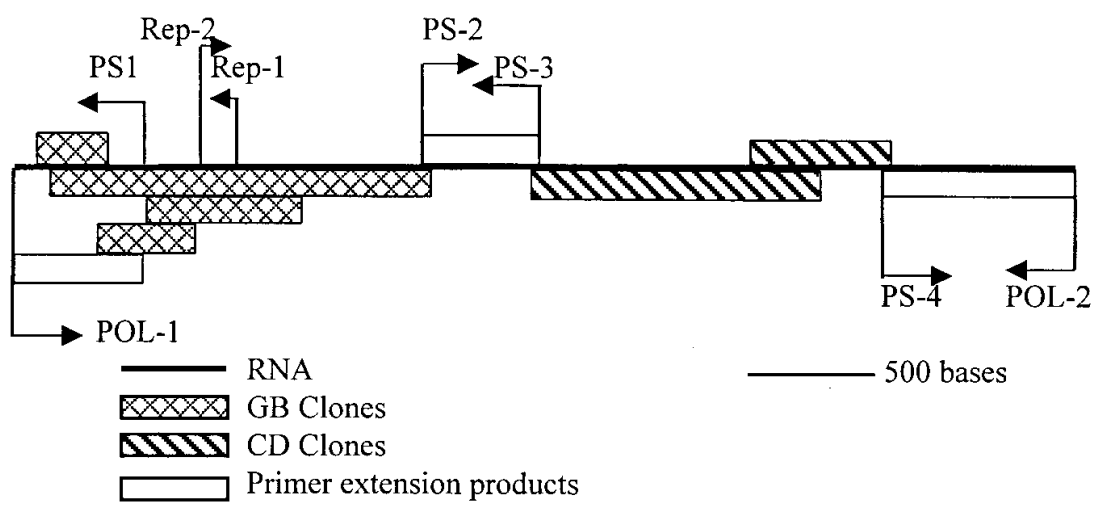

Fig. 1. Map of Pothos latent virus-pigeonpea isolate genomic RNA showing the primer annealing positions and the amplification direction of the eight oligonucleotide primers. mentary DNA (cDNA). Hybridization reactions were detected chromogenically using anti-DIG ALP-antibodies and nitrobluetetrazolium (NBT) and 5-bromo-4chloro-3-indoyl-2-D-galactoside

(BCIP)

substrate (BCIP/NBT) (Roche).

cDNA synthesis and cloning. DNA complementary to the viral RNA was made by the Gubler and Hoffman (5) method using the Universal Riboclone Synthesis System (Promega, Southampton, UK). Purified RNA $(2 \mu \mathrm{g}), 1 \mu \mathrm{g}$ of random hexameric primers, and AMV reverse transcriptase (RT) were used as described in the manufacturer's protocol. After the second strand synthesis, the resulting products were cloned into the EcoRI site of a polymerase chain reaction (PCR) blunt vector, transformed into Escherichia coli TOPO 10 competent cells (Invitrogen, Leek, The Netherlands) and plated on Luria-broth (LB) kanamycin plates. Plasmids from the transformed clones were purified with the Wizard miniprep kit (Promega). cDNA to the viral RNA not contained in the initial sets of cDNA clones was constructed by primer extension using RTPCR as described by Ausubel et al. (1; Fig. $1)$. RT-PCR products were cloned into a TOPO-TA vector (Invitrogen).

Oligonucleotide primers and RT-PCR. For primer extension studies, sequencing, and virus detection, eight virus-specific synthetic oligonucleotide primers, named PS1, PS2, PS3, PS4, Rep-1, Rep-2, POL1, and POL2, were designed from viral RNA sequence and from the published nucleotide sequence of PoLV (23). The primer properties are given in Table 2 and their positions are indicated in Figure 1.

The RT-PCR procedure of MacKenzie et al. (14) was followed for virus detection using total RNA extracts prepared from $100 \mathrm{mg}$ of leaf material using the Plant RNeasy kit (QIAGEN) and Maloney murine leukemia virus (MMLV) RT (Promega). The conditions for PCR were those given by Kumar et al. (10). Amplified products were analyzed in a $1 \%$ agarose gel and stained with ethidium bromide.

Nucleotide sequencing and computer analysis. The nucleotide sequence of the reverse-transcribed viral RNA was determined by the dideoxynucleotide chain termination method using the Dye-Prism

Table 2. Nucleotide sequence and properties of the primers used for primer extension studies by reverse transcriptase-polymerase chain reaction

\begin{tabular}{|c|c|c|c|c|}
\hline Primer & Length (bases) & Sequence $\left(5^{\prime} \rightarrow 3^{\prime}\right)$ & Annealing site in PoLV-PP sequence ${ }^{a}$ & Product size (bp) \\
\hline $\mathrm{POL}^{\mathrm{b}}$ & 21 & GCCTAACCAGCTTGTTGAGAG & $1-21$ & 275 \\
\hline PS1 & 22 & CCTTGAATCCAGCACACATGTC & $254-275$ & \\
\hline PS2 & 25 & GAGATCGAGTTTTGCCAACAACACC & $1,898-1,922$ & 558 \\
\hline PS3 & 23 & CCTGCTGGACTAAGCATAACTTG & $2,434-2,456$ & \\
\hline PS4 & 21 & CTGTTGAGTCATAAAACTACC & $3,638-3,658$ & 678 \\
\hline $\mathrm{POL} 2^{\mathrm{b}}$ & 19 & CCAAGCGTCATTTATAGCC & $4,336-4,354$ & \\
\hline Rep-1 & 25 & CAATCTAGCTCGTTCATACGTGGCG & $1,174-1,198$ & 222 \\
\hline Rep-2 & 21 & GTCAACGTTTGTCGTGGTTTG & $977-997$ & \\
\hline
\end{tabular}

a PoLV-PP $=$ Pothos latent virus -pigeonpea isolate.

${ }^{\mathrm{b}}$ Derived from PoLV sequence (accession no. X87115). 
cycle sequencing kit (Applied Biosystems, Warrington, UK) on plasmid clones containing the cDNA copies made by PCR (9). Selected clones were sequenced twice in both directions using M13 forward and reverse primers, as well as with virus-specific primers. The DNA sequences were analyzed using the University of Wisconsin Genetics Computer Group package version 8.1 (2) on the MRC-HGMP computer (Hinxton, Cambridge, UK). Various computer programs were used to analyze the data.

\section{RESULTS}

Virus isolation. In initial experiments, concentrated extracts from some PSMDaffected pigeonpea leaves, but not extracts from PSMD-free plants, induced a few local necrotic lesions on $C$. quinoa, but systemic wilting and death of $N$. benthamiana 7 to 12 days pi. Such infective inocula induced a maximum of 5 to 8 local lesions on some individual $C$. quinoa plants. By contrast, most inoculated $N$. benthamiana plants developed symptoms. Repetition of this experiment showed that $C$. quinoa and $N$. benthamiana were the only two of nine hosts species tested that were infected using concentrated pigeonpea extracts. Infectivity by this means was obtained on only 6 of 20 occasions from PSMD-affected pigeonpea samples analyzed from Patancheru and Kanukunta in Andhra Pradesh State; Gulbarga in Karnataka State; Rahuri in Maharasthra State; and Puddukkotai in Tamil Nadu State, India. Inoculation of plants with PSMD-affected pigeonpea leaf sap without concentration never resulted in virus isolation.

Experimental host range. Of 30 plant species and cultivars tested, 21 were infected with PoLV-PP (Table 1). Systemic infection was consistent in only three species but, in Gomphrena globosa, the virus was systemic in one of three separate experiments (Table 1). Systemic infection in $N$. benthamiana resulted in wilting of the plant, starting from the apical shoot and spreading downward and laterally, leading ultimately to plant death within 12 days (Fig. 2A). In N. hispens, systemic infection resulted in necrosis which spread to the apical shoot and new growth and also led to plant death. In $N$. clevelandii, inoculated leaves showed dark-brown necrotic lesions, which later coalesced to form large necrotic patches. Systemic necrosis was confined to areas between lateral veins and was often concentrated near the petiole (Fig. 2B). Systemic infection in G. globosa was confined to a few leaves only (Fig. 2C). At 4 weeks pi, most of the systemic hosts were dying. Based on the host response and susceptibility to virus infection, C. quinoa was a sensitive local lesion host, $N$. benthamiana a very sensitive systemic host, and $N$. clevelandii a suitable propagation host. In other hosts, virus was recovered from inoculated leaves only (Table
1). Mechanical inoculation of healthy pigeonpea cv. ICP8863 (a cultivar very susceptible to PSMD that is grown widely in the Indian peninsular) with virus-infected sap of $C$. quinoa induced large necrotic areas on inoculated leaves 5 days pi; however, uninoculated apical leaves developed no symptoms (Fig. 3). Virus was detected in inoculated but not in uninoculated leaves of pigeonpea as assessed by back inoculation to $C$. quinoa.

PoLV-PP was maintained by serial passages in $N$. clevelandii but, after 8 to 10 serial passages, a diminishing in symptom severity was noted and infected $N$. benthamiana showed only a mild systemic chlorosis of leaves or no symptoms (Fig. 2D).

Properties in vitro. In assays to $C$. quinoa, PoLV-PP infectivity was retained without noticeable loss when sap of infected $N$. clevelandii leaves was stored at room temperature (approximately $18^{\circ} \mathrm{C}$ ), 4 , or $-20^{\circ} \mathrm{C}$ for up to 32 days, and when infected whole $N$. clevelandii leaves were stored at $4^{\circ} \mathrm{C}$ and $-20^{\circ} \mathrm{C}$ for 90 days, the longest periods tested.

When 10-fold serial dilutions (up to $10^{-10}$ ) of infected $N$. clevelandii leaf sap in phosphate buffer were inoculated mechanically to $C$. quinoa and $N$. benthamiana, symptoms usually developed from most inocula, but the lesion number in $C$. quinoa decreased greatly, and systemic wilting and death of the plant was delayed in $N$. benthamiana after diluting $10^{-8}$. This experiment, repeated three times, resulted in symptoms in all $N$. benthamiana plants inoculated with the highest dilution $\left(10^{-10}\right)$, whereas symptoms in $C$. quinoa occurred with dilutions from $10^{-7}$ to $10^{-9}$.

Soil transmission of PoLV-PP. In both kinds of soil transmission experiment, all $10 \mathrm{~N}$. clevelandii and $10 \mathrm{~N}$. benthamiana

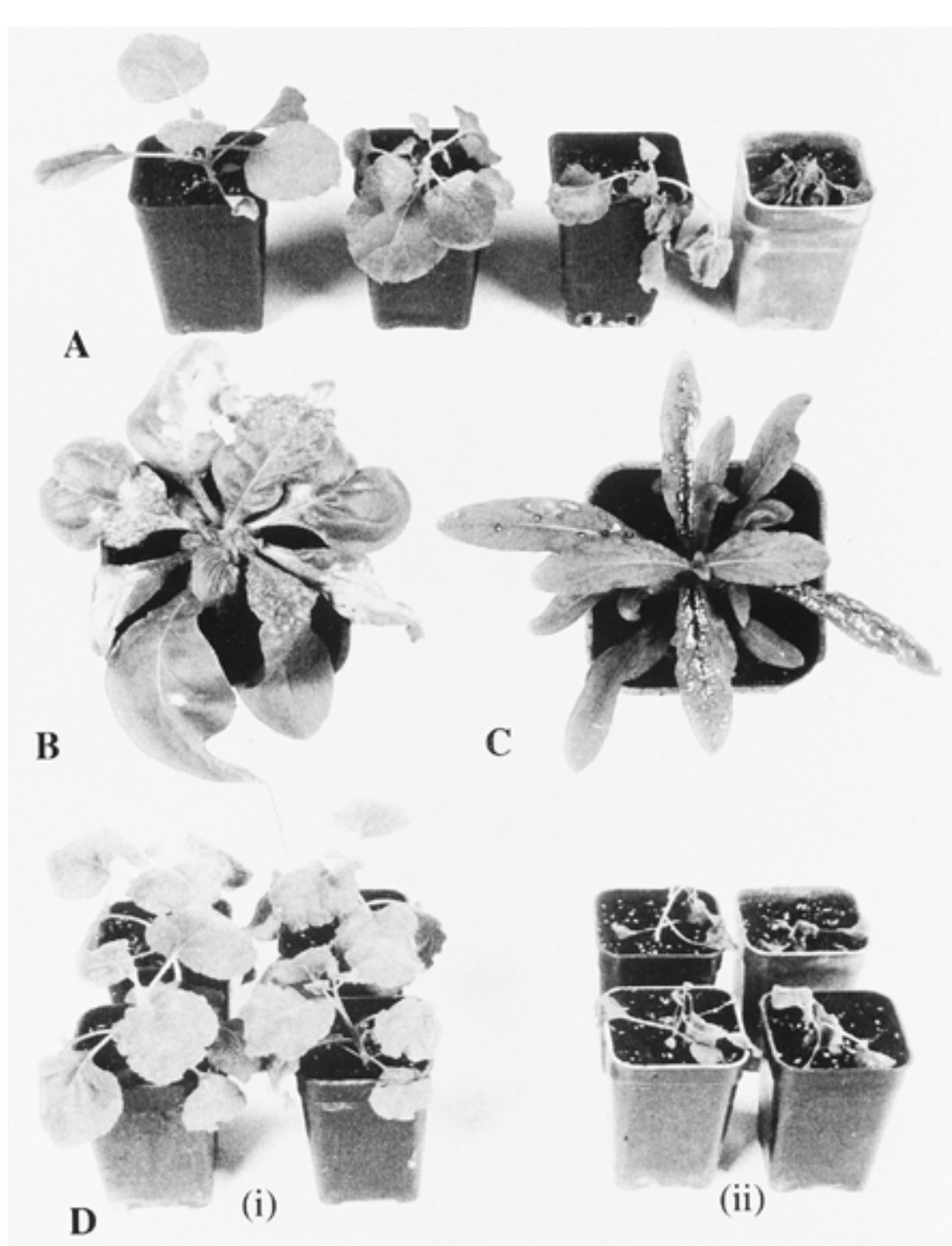

Fig. 2. Symptoms of Pothos latent virus-pigeonpea isolate on $\mathbf{A}$, Nicotiana benthamiana showing progressive systemic wilting 2,6 , and 12 days post-inoculation (pi) and death 16 days pi; B, $N$. clevelandii showing systemic necrosis; C, Gomphrena globosa showing systemic necrotic lesions with purple margins; and D, N. benthamiana showing attenuation of symptom severity following serial inoculations (i) of wild type isolate (ii). 
plants became infected with PoLV-PP and showed typical symptoms of systemic infection 13 to 18 days after the experiments began, whereas none of the control plants showed any symptoms or were infected with PoLV-PP. This demonstrates the ability of PoLV-PP to infect plants through soil. By contrast, none of the 20 pigeonpea test plants used in the two kinds of experiment developed any symptoms and all were negative for PoLV-PP in ELISA.

Properties of purified virus particle preparations. In sucrose density gradients, purified virus particles sedimented as a single zone corresponding to a single main peak of absorbance. Virus preparations formed a single buoyant density band in cesium chloride and cesium sulfate gradients with densities of 1.34 and $1.27 \mathrm{~g} \cdot \mathrm{cc}^{-1}$, respectively. Purified virus particles had a maximum UV-absorption at $A_{258 \mathrm{~nm}}$, a minimum at $A_{242 \mathrm{~nm}}$, and an $A_{260 / 280}$ ratio of 1.78. PoLV-PP concentration, determined by assuming an extinction coefficient of 4.5 optical density (OD) at $A_{260 \mathrm{~nm}}$ equal to
$1 \mathrm{mg}$ (15), was $4 \mathrm{mg}$ of virus per $100 \mathrm{~g}$ of leaf.

Purified virus particle preparations contained many isometric particles approximately $30 \mathrm{~nm}$ in diameter, with slightly angular edges and a knobbed surface (Fig. 4). C. quinoa and N. clevelandii inoculated with such preparations developed symptoms 5 days pi, confirming that purified virus particle preparations were infectious. When inoculated to pigeonpea (cv. ICP8863), purified PoLV-PP preparations infected and induced necrosis on inoculated leaves but failed to spread systemically.

Virus particle protein and serological relationships. Purified PoLV-PP particle preparations contained a single major protein species with an estimated size of 43 to $45 \mathrm{kDa}$ (results not shown). The homologous antiserum had a titer of 1:1024 and reacted with virus in purified preparations and in infected leaf sap of $N$. clevelandii, but not with leaf sap from PSMD-affected pigeonpea or uninfected $N$. clevelandii. In gel double-diffusion tests, the virus reacted

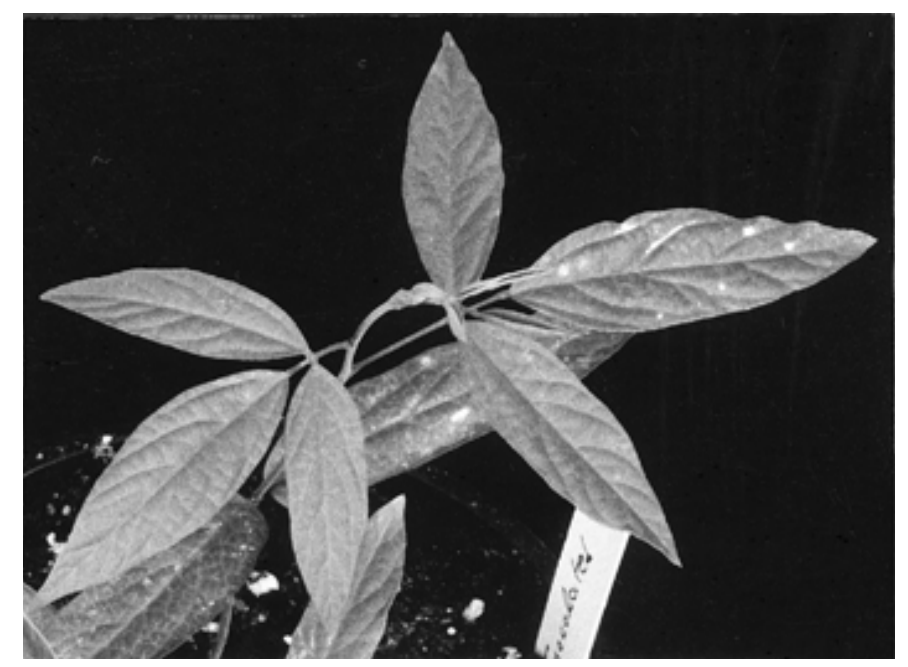

Fig. 3. Local large necrotic lesions in leaves of pigeonpea genotype ICP8863 induced by mechanical inoculation with purified preparations of Pothos latent virus-pigeon pea isolate.

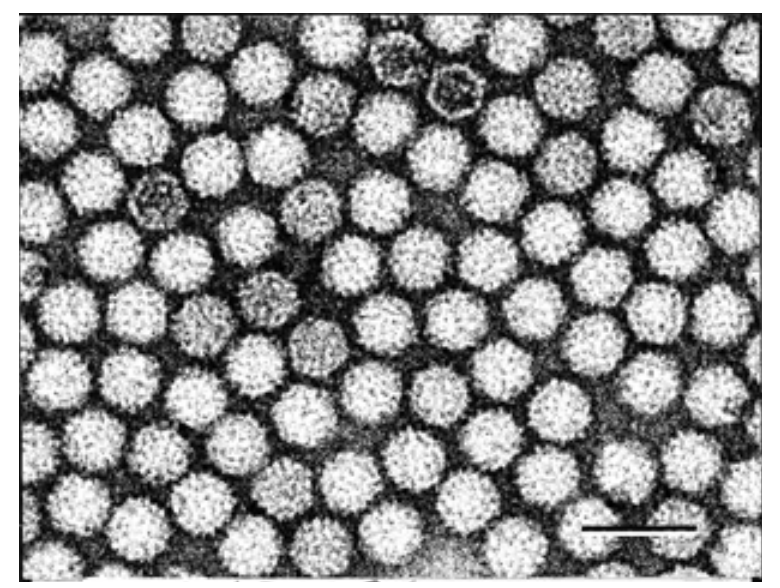

Fig. 4. Transmission electron micrograph of purified Pothos latent virus-pigeonpea isolate particle preparations stained with phosphotungstic acid. Bar represents $50 \mathrm{~nm}$.

to the dilution end-point of antiserum to the type isolate of PoLV. When this isolate and PoLV-PP were placed in adjacent wells, each virus reacted with homologous and heterologous antisera without the formation of spurs, indicating that the two viruses are serologically indistinguishable in this test. No reaction was detected in tests of PoLV-PP against antisera to 10 other viruses in the family Tombusviridae.

Characterization of virus nucleic acid. Purified virus particle preparations contained three RNA species of about 4,300, 2,700, and 1,500 nucleotides (nt) (Fig. 5A). The concentration of the largest RNA species was greater than that of the other two species. Viral RNA did not bind to oligo $\mathrm{dT}_{30}$ latex beads, indicating a lack of polyadenylation at the $3^{\prime}$ end. Unfractionated purified nucleic acid preparations were infectious and induced symptoms typical of the virus when inoculated to $C$. quinoa and $N$. clevelandii. Plants of $N$. benthamiana and $C$. quinoa inoculated with the largest RNA species (4,300 nt) alone induced typical symptoms of the virus 4 days pi, but not when inoculated with the two smaller RNA species either alone or together.

In Northern blot hybridization, the two smaller RNAs did not react with the cDNA

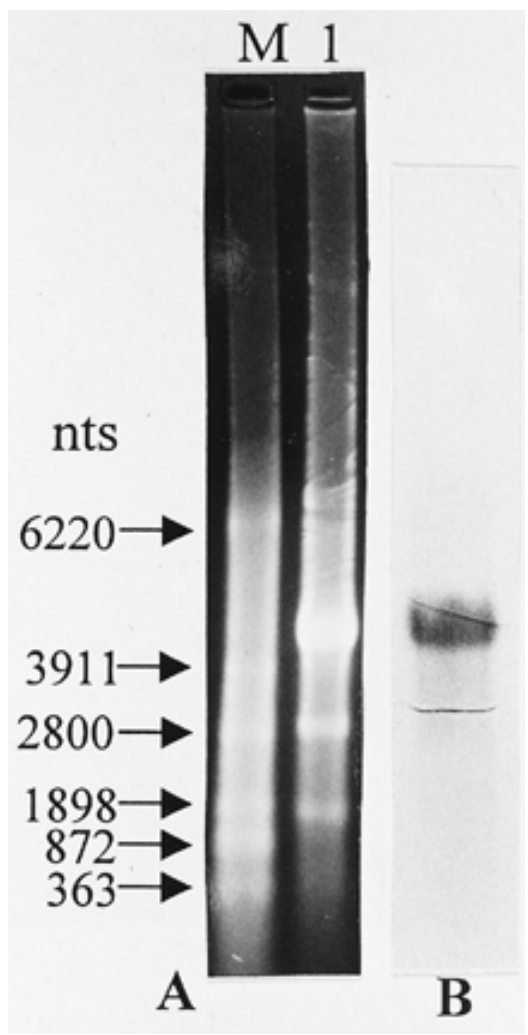

Fig. 5. A, Resolution in $1 \%$ agarose gel of Pothos latent virus-pigeonpea isolate RNA from purified virus particle preparations (lane 1) and RNA size markers (lane M). B, Detection of the largest RNA species in virus particle preparations using the probe prepared from the $5^{\prime}$ end of the virus genome. 
probe corresponding to the $5^{\prime}$ end of the replicase gene (Fig. 5B), but did react with a probe prepared from the coat protein and 3 ' terminal region of the large RNA (data not shown), suggesting the subgenomic nature of the two smaller RNAs.

cDNA synthesis and nucleotide sequencing. cDNA clones containing inserts of more than $200 \mathrm{bp}$ were selected for sequencing. Four overlapping clones (GB $3.9,4.2,4.4$, and 5.5) were identified that gave a sequence of $1,847 \mathrm{nt}$. Two other overlapping clones (CD 4.22 and 6.1), which did not overlap with the GB clones, contained 1,341 nt, giving a total of 3,118 nt for the genomic RNA. The sequence corresponding to the $3,118 \mathrm{nt}$ of the viral RNA was assessed for homology with sequences present in the EMBL database using the program FASTA (18). This showed that the PoLV-PP RNA sequence had about $90 \%$ homology with the genomic RNA of PoLV and to a lesser extent to several species in the genera Tombusvirus, Carmovirus, Dianthovirus, Necrovirus, and Machlomovirus of the family Tombusviridae (data not shown). Some similarities were also detected to Barley yellow dwarf virus, Olive latent virus, and Carrot mottle virus (data not shown). Compared with PoLV, similarities detected with other members of the family Tombusviridae were not significant, other than in the conserved domains of the replicase and capsid proteins, a characteristic feature of species in this family (24). Pairwise comparisons of the sequence obtained from the four PoLV-PP clones were made with the PoLV RNA sequence (Accession No. X87115) using the programs PILEUP and BESTFIT. This showed that the sequence obtained from the GB clones corresponded to the $5^{\prime}$ end of the PoLV-RNA relating to open reading frame (ORF) 1 and ORF2; information from the CD clones corresponded to the capsid protein and movement protein genes. The longest overlapping clones gave information for only 3,118 nt; therefore, cDNA for the remaining part of the genomic RNA was obtained, using primer extension. Four synthetic oligonucleotide primers (PS1, PS2, PS3, and PS4) were designed using the sequence information from the GB and CD clones (Table 2, Fig. 1). Primers PS2/PS3 were used to amplify the gap between the GB and CD clones and produced a product of $558 \mathrm{bp}$. Because of the high sequence similarity with PoLV, the regions toward the $5^{\prime}$ and $3^{\prime}$ ends of PoLV RNA were used to design POL1 and POL2 primers and were used in combination with primers PS1 and PS4. Primers POL1/PS1 gave a product of $275 \mathrm{bp}$ towards the $5^{\prime}$ end and primers PS4/POL2 amplified a product of $678 \mathrm{bp}$ towards the 3' end (results not shown). Each of the DNAs was cloned and three independent clones of each were sequenced on both strands. Thus, a sequence spanning the full length of the PoLV-PP genome was obtained, excluding a few nucleotides at the extreme $5^{\prime}$ and $3^{\prime}$ ends of the RNA. This sequence was determined to be 4,354 nt (accession no. AJ243370; not shown). It is predicted to contain 5 ORFs (results not shown). ORF1 begins with AUG at nucleotide position 125 and terminates with an amber codon (UAG) at nucleotide position 793, resulting in a product of $25 \mathrm{kDa}$. If readthrough of the amber codon occurs, a product of $84 \mathrm{kDa}$ would be synthesized terminating at an opal codon (UGA) at position 2,344 (ORF2). ORF3 spans nucleotides 2,356 to 3,474 and encodes a protein of about $41 \mathrm{kDa}$. ORF4 spans nucleotides 3,569 to 4,297 and encodes a protein of about $27 \mathrm{kDa}$. ORF5, which is completely overlapped by ORF4, encodes a protein in a different reading frame. It initiates with an AUG codon at position 3,700 and encodes a putative protein of 14 $\mathrm{kDa}$ before terminating at an ochre codon (UAA) at position 4,092.

The putative genome organization and deduced amino acid sequence of the five ORFs is similar to that of PoLV and of Cucumber leaf spot virus (CLSV), a virus with close similarities to PoLV (17). The nucleotide sequence of PoLV-PP is 93 and $64 \%$ identical to PoLV and CLSV, respectively, and all five ORFs encode proteins with a high degree of identity in their amino acid sequence to those of PoLV (Table 3). Because of the high similarity with PoLV, the five ORFs of PoLV-PP may be regarded as having an expression strategy and functions similar to those corresponding ORFs of PoLV. These are reported as ORF1, the read-through domain; ORF2, part of the replicase encoding domain; ORF3 encodes the capsid protein; ORF4 encodes a virus movement protein; and ORF5 encodes a protein responsible for symptom expression (22).

Virus detection. PoLV-PP was detected reliably by DAC-ELISA in $N$. clevelandii and in other experimentally infected herbaceous hosts. For these assays, antiserum was diluted up to $1: 8,000$, at which level no significant reaction with healthy (asymptomatic) leaf extracts or buffer was detected (each with $A_{405}$ of $<0.4$ ) compared to the high values $\left(A_{405}>2.6\right)$ for experimentally infected herbaceous plants. In various dilutions of antiserum and antigen in DAC-ELISA, there was no significant difference between the OD values obtained from healthy $\left(A_{405}\right.$ approximately 0.3$)$ and
PSMD-affected ( $A_{405}$ approximately 0.4$)$ pigeonpea in many assays, indicating that DAC-ELISA may not be sensitive enough to detect PoLV-PP in pigeonpea or that plants did not contain the virus. However, assays on leaf samples from the pigeonpea plants (cv. ICP8863) inoculated mechanically with purified PoLV-PP particle preparations detected the virus in inoculated but not in uninoculated leaves. DAC-ELISA of pothos (Scindapsus aureus) plants collected from various locations of Andhra Pradesh State, India, also failed to detect PoLV-PP.

For greater sensitivity, the RNA nucleotide sequence was used to design two primers, REP-1 and REP-2, for RT-PCR amplification of a 222-nt product corresponding to the $5^{\prime}$ end of the replicase gene (Table 2 and Fig. 1). When used with viral RNA from purified PoLV-PP particle preparations and total RNA from experimentally infected herbaceous hosts, a PCR product of expected size was obtained readily (results not shown). RT-PCR of 56 PSMD-affected and 37 healthy pigeonpea plants, obtained from material maintained in a growth chamber and from the field, detected PoLV-PP in only six PSMD-affected and three healthy samples. From several individual plants of healthy and PSMD-affected pigeonpeas in which RTPCR failed to detect PoLV-PP, $25 \mathrm{~g}$ of leaf was concentrated and the RNA isolated from this extract was tested by RT-PCR. No PCR product of the expected size was detected in any of these assays.

\section{DISCUSSION}

The simple protocol for concentrating pigeonpea leaf sap, diluted in excess buffer to decrease the inactivating and/or inhibitory effects of host polyphenols, resulted in the occasional isolation of a novel tombusvirus. This is the first report of a tombusvirus in pigeonpea. The virus is shown to be very similar to PoLV and we therefore consider it to be a pigeonpea isolate of PoLV (PoLV-PP). PoLV-PP exhibited the characteristic features of species in the genus Aureusvirus of the family Tombusviridae, including the following: icosahedral particles, a single coat protein species of approximately $44 \mathrm{kDa}$, monopartite single-stranded RNA genome without a poly(A) tail, and encapsidation of 2 subgenomic RNAs (16). The genome of tombusviruses acts as an mRNA for the expression of the $5^{\prime}$ proximal genes (ORF1

Table 3. Pairwise comparison of Pothos latent virus (PoLV), PoLV-pigeonpea isolate (PP), and Cucumber leaf spot virus (CLSV) amino acid sequences

\begin{tabular}{lccccc}
\hline & \multicolumn{5}{c}{ Amino acid sequence identity (\%) } \\
\cline { 2 - 6 } Virus pair & ORF1 $^{\mathbf{a}}$ & ORF2 & ORF3 & ORF4 & ORF5 \\
\hline PoLV-PP/PoLV & 96 & 96 & 92 & 97 & 98 \\
PoLV-PP/CLSV & 64 & 80 & 39 & 77 & 59 \\
CLSV/PoLV & 63 & 87 & 37 & 78 & 60 \\
\hline
\end{tabular}

${ }^{\mathrm{a}} \mathrm{ORF}=$ open reading frame. 
and 2), but the $3^{\prime}$ genomic RNA is expressed via two $3^{\prime}$ coterminal subgenomic RNAs, and the encapsidation of subgenomic RNAs is reported for several tombusviruses (24). Our data suggest that this also occurs with PoLV-PP. However, in serological tests, the virus reacted with antiserum to only 1 (PoLV) of 11 virus species in this family tested. PoLV is the type member of the newly proposed genus Aureusvirus of the family Tombusviridae (16,22). The PoLV-PP genome contains five ORFs and, although no in vitro translation studies were made in this study, the putative amino acid sequence deduced from the five ORFs showed 92 to $98 \%$ sequence similarity with PoLV (Table 3); therefore, the functional properties of the proteins expressed from these five ORFs are likely to be similar to those of PoLV (22-24).

Some tombusviruses develop attenuated symptoms following serial passages in experimental hosts due to the generation of defective interfering (DI) RNAs (24). This ability to generate or support DI RNAs is one feature considered to differentiate tombusvirus strains (24). Possibly, the attenuation of symptoms following serial passage of PoLV-PP in N. clevelandii could be due to the generation of DI RNAs that interfere with replication. Alternatively, the attenuation of symptoms could result from the selection of a distinct isolate from the quasi-species population of PoLV-PP. However, it is noteworthy that the serial passage of PoLV in herbaceous hosts did not result in symptom variants and that no DI RNAs were reported in PoLV, nor did PoLV support the replication of DI RNAs from other tombusviruses (22). Therefore, although PoLV-PP and PoLV are genetically very similar, further studies on the factors contributing to symptom attenuation following serial passage of PoLV-PP in herbaceous hosts may determine if it is a distinct strain of PoLV.

When pigeonpea was inoculated with purified PoLV-PP particle preparations, the preparations failed to induce PSMD symptoms and the virus was detected only in uninoculated leaves of these plants. Furthermore, despite the fact that PoLV-PP was initially isolated from PSMD-affected pigeonpea, it was detected in only $10.7 \%$ of PSMD-affected pigeonpea samples from various locations in India and also in $8.1 \%$ of pigeonpea plants unaffected with PSMD. These results show that PoLV-PP is not the causal agent of PSMD. Indeed, very recently, the probable causal agent of PSMD was shown to be a virus with thin, highly flexuous filamentous particles, similar in appearance to tenuiviruses (11). PoLV-PP was not detected in pothos plants in India.

The in vitro properties of PoLV-PP indicate that is extremely stable; therefore, the difficulty in isolating the virus from infected pigeonpea suggests that it occurs only in very low concentration and/or is erratically distributed in, or on, pigeonpea leaves. The precise conditions under which PoLV-PP is associated in approximately $9 \%$ of pigeonpea field samples in India is not clear. Tombusviruses are very stable and are found often in natural environments (surface waters and soils) from which plant hosts can acquire them without the assistance of vectors (6). The soil transmission experiments with herbaceous test plants demonstrate clearly that such transmission does occur with PoLV-PP. However, none of the pigeonpea test plants became infected by this means. This indicates either that PoLV-PP does not infect pigeonpea roots or that it does not move systemically in this species. This later possibility is supported by the ability to detect PoLV-PP in inoculated, but not in uninoculated, leaves of pigeonpea plants inoculated mechanically with purified virus preparations. If this is so, it seems likely that the detection of PoLV-PP in pigeonpea in India is due to virus particles attached to soil or plant debris that contaminates the surface of leaves of fieldgrown plants through the effects of wind and/or rain. Such contamination may or may not result in local infection of pigeonpea. This later possibility is supported by the fact that PoLV-PP was recovered from a field sample of pigeonpea from India by gently sonicating $15 \mathrm{~g}$ of leaves in phosphate buffer to remove the leaf surface contaminants (while minimizing any direct damage to leaves), concentrating the buffer extract by ultracentrifugation, and using it to inoculate $N$. benthamiana plants.

This article, therefore, emphasizes the need for the careful evaluation of viruses from field-grown plants, especially from those with diseases of unknown etiology.

\section{ACKNOWLEDGMENTS}

We thank our colleagues at SCRI, G. Duncan, W. McGavin, and C. McQuade, for technical help; and G. Martelli for generous gifts of PoLV inoculum and homologous antiserum.

\section{LITERATURE CITED}

1. Ausubel, F. M., Brent, R., Kingston, R. E., Moore, D. D., Seidman, J. G., Smith, J. A., and Struhl, K. 1994. The polymerase chain reaction. Curr. Prot. Mol. Biol. 15.03-15.87.

2. GCG. 1994. Program Manual for the Wisconsin Package, version 8. Genetics Computer Group, Madison, WI.

3. Ghanekar, A. M., Sheila, V. K., Beniwal, S. P. S., Reddy, M. V., and Nene, Y. L. 1992. Sterility mosaic of pigeonpea. Pages 415-428 in: Plant Diseases of International Importance, Volume 1, Diseases of Cereals and Pulses. U. S. Singh, A. N. Mukhopadhyay, J. Kumar, and H. S. Chaube, eds. Prentice Hall, Upper Saddle River, NJ.

4. Gispert, C., Perring, T. M., and Creamer, R. 1998. Purification and characterization of peach mosaic virus. Plant Dis. 82:905-908.

5. Gubler, U., and Hoffman, B. J. 1983. A simple and very efficient method for generating cDNA libraries. Gene 25:263-269.

6. Jones, A. T. 1993. Virus transmission through soil and by soil-inhabiting organisms in diagnosis. Pages 73-99 in: Diagnosis of Plant Vi- rus Diseases R. E. F. Matthews, ed. CRC Press, Boca Raton, FL.

7. Jones, A. T., McGavin, W. J., Brunt, A. A., and Phillips, S. 2000. Elderberry latent virus: its relationship to Pelargonium ringspot virus and its identification as a distinct member of the genus Carmovirus, family Tombusviridae. Ann. Appl. Biol. 136:147-152.

8. Kannaiyan, J., Nene, Y. L., Reddy, M. V. Ryan, J. G., and Raju, T. N. 1984. Prevalence of pigeonpea diseases and associated crop losses in Asia, Africa and the Americas. Trop. Pest Manag. 30:62-71.

9. Kumar, P. L., Fenton, B., and Jones, A. T. 1999. Identification of Cecidophyopsis mites (Acari: Eriophyidae) based on variable simple sequence repeats of ribosomal DNA internal transcribed spacer-1 sequence via multiplex PCR. Insect Mol. Biol. 8:347-358.

10. Kumar, P. L., Fenton, B., Jones, A. T., and Reddy, D. V. R. 1998. Identification of Aceria cajani, the mite vector of the agent of pigeonpea sterility mosaic disease based on analysis of ribosomal DNA internal transcribed spacer sequences. Training Course Manual. ICRISAT, Patancheru, India.

11. Kumar, P. L., Jones, A. T., Sreenivasulu, P., and Reddy, D. V. R. 2000. Breakthrough in the identification of the causal virus of pigeonpea sterility mosaic disease J. Mycol Plant Pathol. 30:249.

12. Laemmli, U. K. 1970. Cleavage of structural proteins during the assembly of the head of bacteriophage T4. Nature 277:680-685.

13. Lemmetty, S., Latvala, S., Jones, A. T., Susi, P., McGavin, W. J., and Lehto, K. 1997. Purification and properties of a new virus from black currant, its affinities with nepoviruses, and its close association with black curran reversion disease. Phytopathology 87:404413.

14. MacKenzie, D. J., McLean, M. A., Mukerji, S., and Green, M. 1997. Improved RNA extraction from woody plants for the detection of viral pathogens by reverse transcriptionpolymerase chain reaction. Plant Dis. 81:222226.

15. Martelli, G. P., Quacquarelli, A., and Russo, M. 1971. Tomato bushy stunt virus. CMI/AAB Descriptions of Plant Viruses No. 69. Wellesbourne, UK.

16. Martelli, G. P., Russo, M., Rubino, L., and Sabanadzovic, S. 1998. Aureusvirus, a novel genus in the family Tombusviridae. Arch. Virol. 143:1847-1851

17. Miller, J. S., Damude, H., Robbins, M. A., Reade, D. R., and Rochon, D. M. 1997. Genome structure of Cucumber leaf spot virus: sequence analysis suggests it belongs to a distinct species within the Tombusviridae. Virus Res. 52:51-60.

18. Pearson, W. R., and Lipman, D. J. 1988. Improved tools for biological sequence comparison. Proc. Natl. Acad. Sci. USA 85:24442448.

19. Reddy, D. V. R., Mayo, M. A., Naidu, R. A., and Sherwood, J. L. 1995. Laboratory Exercises for a Training Course on the Detection and Identification of Viruses. ICRISAT, Patancheru, India.

20. Reddy, M. V., Raju, T. N., and Lenne, J. M. 1998. Diseases of pigeonpea. Pages 540-558 in: The Pathology of Food and Pasture Legumes. D. J. Allen and J. M. Lenne, eds. CABI, Wallingford.

21. Reddy, M. V., Reddy, D. V. R., and Sacks, W. R. 1994. Epidemiology and management of sterility mosaic disease of pigeonpea. Pages 29-32 in: Proc. Int. Symp. Rose Rosette and Other Eriophyid Mite-Transmitted Plant Disease Agents of Uncertain Etiology. Iowa State University, Ames.

22. Rubino, L., and Russo, M. 1997. Molecular 
analysis of the pothos latent virus genome. J. Gen. Virol. 78:1219-1226.

23. Rubino, L., Russo, M., and Martelli, G. P. 1995. Sequence analysis of Pothos latent virus genomic RNA. J. Gen. Virol. 76:28352839.
24. Russo, M., Burgyan, J., and Martelli, G. P. 1994. The molecular biology of Tombusviridae. Adv. Virus Res. 44:381-428.

25. Sabanadzovic, S., Boscia, D., Saldarelli, P., Martelli, G. P., Lofortezza, R., and Koenig, R. 1995. Characterisation of pothos (Scindapsus aureus) virus with unusual properties. Eur. J. Plant Pathol. 101:171-182.

26. Sambrook, J., Fritsch, E. F., and Maniatis, T. 1989. Molecular Cloning Laboratory Manual, 2nd ed. Cold Spring Harbor Laboratory, Cold Spring Harbor, NY. 